\title{
Cultivo de sequeiro da mamona adubada com casca de mamona e fertilizante nitrogenado ${ }^{1}$
}

\author{
Marcos A. da Silva², Francisco E. de A. Silva², Edivan da S. Nunes Júnior ${ }^{2}$, \\ Fabiana X. Costa ${ }^{2} \&$ José S. de Melo Filho ${ }^{2}$
}

\begin{abstract}
RESU M O
O bjetivou-se com este trabalho avaliar o crescimento e produção da mamoneira (Ricinus communis L., CV. BRS Energia) cultivada em regime de sequeiro em função da adubação combinada de casca de mamona na forma moída e natural com doses crescentes de fertilizante nitrogenado. 0 experimento foi realizado entre setembro de 2009 a março de 2010, no Campus IV/U EPB. Realizou-se o plantio em vasos plásticos de $60 \mathrm{~L}$ preenchidos com $58 \mathrm{~kg}$ de solo. U tilizou-se o delineamento de blocos ao acaso em arranjo fatorial $2 \times 4$, sendo aplicado 3 t ha-1 de casca de mamona em duas formas de utilização (natural e moída) e quatro doses de nitrogênio $\left(0,30,60,90 \mathrm{~kg} \mathrm{ha}^{-1}\right)$, com quatro repetições totalizando 32 parcelas. Verifica-se que a adubação com a casca moída foi superior a casca natural. Para a massa seca do cacho, área foliar por planta e número de folhas a dosagem $90 \mathrm{~kg} \mathrm{ha}^{-1}$ de $\mathrm{N}$ foi superior às demais. Já para o número de nós foi a dose de $60 \mathrm{~kg} \mathrm{ha}^{-1}$ de $\mathrm{N}$. A casca de mamona usada de forma racional, como adubo, contribui para redução de custos ao produtor e incrementos na fertilidade do solo.
\end{abstract}

Palavras-chave: semiárido, Ricinus communis L., fertilização

\section{Castor bean cultivated under rainfed conditions with the castor bean bark and nitrogen fertilization}

\begin{abstract}
AB STRACT
The objective of this research was to evaluate the growth and production of castor bean (Ricinus communis L.) BRS Energia in rainfed cultivation under combined fertilization of castor bean bark in a natural and ground forms and with increasing levels of nitrogen. The experiment was conducted during September, 2009 to March, 2010, at Campus IV/U EPB. The planting was done in $60 \mathrm{~L}$ pots filled with $58 \mathrm{~kg}$ of soil. U sing a randomized block design in a $2 \times 4$ factorial, with two kinds of bark of castor bean (natural and ground) in the dose of $3 \mathrm{t} \mathrm{ha}^{-1}$ and four rates of nitrogen $\left(0,30,60,90 \mathrm{~kg} \mathrm{ha}^{-1}\right)$ with four replications. It was verified that fertilization with the ground bark was superior than natural bark. For the dry mass of the bunch, leaf area per plant, and leaf number, dose of $90 \mathrm{~kg} \mathrm{ha}^{-1}$ of $\mathrm{N}$ was better than the others. While for the number of nodes the dose of $60 \mathrm{~kg} \mathrm{ha}^{-1}$ of $\mathrm{N}$ was better. The bark of castor bean used in a rational way, as fertilizer, contributes to reduce cost of production and increases the soil fertility.
\end{abstract}

Key words: semi-arid, RicinuscommunisL., fertilization

Parte do Experimento PIBIC/U EPB/CN Pq do primeiro autor. Trabalho apresentado durante a II Reunião Sulamericana para Manejo e Sustentabilidade da Irrigação em Regiões Áridas e Semiáridas, Cruz das Almas, BA - 03 a 07 de abril de 2011

2 D AE/U EPB, Curso de Ciências Agrárias. Sítio Cajueiro, s/n, CEP 58884-000, Catolé do Rocha, PB. Fone: (83) 3441-2411. E-mail: marcouepb@yahoo.com.br; edivanjunio@uepb.edu.br; evandro19silva@hotmail.com; fabixavierster@hotmail.com; sebastiaouepb@yahoo.com.br 


\section{INTRODUÇÃO}

A busca mundial pela sustentabilidade ambiental, com base na substituição progressiva dos combustíveis minerais derivados do petróleo por combustíveis renováveis de origem vegetal, dentre eles o biodiesel do óleo da mamona, criou-se uma perspectiva real para a expansão do cultivo da mamona em escala comercial (Lira \& Barreto, 2009).

A mamoneira é uma planta nativa de países de clima tropical e subtropical além de ser rústica, utiliza pouco agrotóxico e adapta-se perfeitamente a região semiárida (Freitas \& Fredo, 2005). O cultivo da mamona no semiárido surge como uma vertente de atuação nas áreas econômicas, ambiental e social. Gera emprego e renda, fortalecendo a economia agrícola, principalmente à agricultura familiar (Azevedo \& Beltrão, 2007).

A mamoneira para crescer, desenvolver e produzir satisfatoriamente necessita de um manejo nutricional adequado e de suprimento hídrico diferenciado nas suas fases fenológicas, o que requer manejo compatível com sua capacidade de retirada de água do solo; desta forma, o manejo e a qualidade da água podem implicar em redução ou aumento da produtividade (Freitas et al., 2010).

É provável que a mamoneira utilize de forma eficiente, o suprimento hídrico disponível no início do ciclo, e consiga assegurar boas produtividades, mesmo após o término da estação chuvosa ou com a suspensão do suprimento hídrico (Távora \& Barbosa Filho et al., 2010).

A mamoneira é muito exigente em nutrientes, considerada esgotadora de solos, tendo produtividade muito alta em solos com alta fertilidade natural ou que receberam adubação em quantidade adequada (Severino et al., 2005).

$\mathrm{O}$ adubo mineral tem resposta rápida às plantas, já o adubo orgânico liberação gradual dos nutrientes (Maia et al., 2008). A casca de fruto de mamoneira é um material que, atualmente, é descartado ou, utilizado como adubo ou combustível na geração de calor (Lopes et al., 2011).

O nitrogênio é o nutriente mais limitante para muitas culturas no mundo, e o seu uso eficiente é de extrema importância econômica para os sistemas de produção (Rodrigues et al., 2010).

Existe a carência de informações sobre a resposta no cultivo de oleaginosas à adubação (Lima et al., 2011). É importantíssimo um manejo cultural adequado, para obtenção de aumentos na produtividade. Pois mesmo tendo grande importância socioeconômica no Nordeste a cultura da mamona apresenta produtividade baixa e a cadeia produtiva ainda necessita de ajustes e aprimoramentos.
Desta forma, objetivou-se com este trabalho avaliar o crescimento e produção da mamoneira BRS Energia cultivada em regime de sequeiro em função da adubação combinada de casca de mamona na forma moída e natural com doses crescentes de nitrogênio.

\section{Material E MÉtodos}

O experimento foi conduzido na área experimental do Campus IV da Universidade Estadual da Paraíba, entre setembro de 2009 a março de 2010, no município de Catolé do Rocha em parceria com o Centro Nacional de Pesquisa de Algodão.

O município fica a $272 \mathrm{~m}$ de altitude, $6^{\circ} 20^{\prime} 38^{\prime \prime} \mathrm{S}$ de Latitude e $37^{\circ} 44^{\prime} 48^{\prime \prime}$ O de Longitude, localizando-se no Sertão Paraibano de clima quente e seco, cuja temperatura média anual é de 27 ${ }^{\circ} \mathrm{C}$. Foi utilizado a cultivar BRS Energia, produzido pela Embrapa Algodão, sendo o plantio realizado em vasos plásticos de $60 \mathrm{~L}$ preenchidos com $58 \mathrm{~kg}$ de material de solo tipo Neossolo Flúvico.

O solo utilizado para o cultivo da mamona apresenta classificação textural de Franco Argilo Arenosa (Tabela 1A). O teor de matéria orgânica está mostrado na Tabela 1B.

A adubação química juntamente com a casca moída e natural foi aplicada toda na fundação. A adubação nitrogenada, usando como fonte uréia, e o fósforo, usando o superfosfato simples, assim como a casca moída e natural, foram misturados e homogeneizados ao solo com suas devidas quantidades em cada tratamento, sendo em seguida semeadas as sementes da mamona BRS Energia em cada vaso.

Observa-se na Tabela 2, a composição química da casca de mamona usada para adubação do solo no qual cultivou-se a mamona.

O delineamento experimental foi o de blocos ao acaso em arranjo fatorial $2 \times 4$, sendo representando duas formas de utilização da casca de mamona (natural e moída) na quantidade de $3 \mathrm{t} \mathrm{ha}^{-1}$ e referente as dosagens de nitrogênio $(0,30,60,90$ $\mathrm{kg} \mathrm{ha}^{-1}$ ) com 4 repetições totalizando 32 unidades experimentais. Em todos os tratamentos foi utilizada uma adubação fixa de $\mathrm{P}_{2} \mathrm{O}_{5}$ na quantidade de $30 \mathrm{~kg} \mathrm{ha}^{-1}$.

A semeadura foi realizada nos vasos com distribuição de três a quatro sementes por cova (Diniz et al., 2009a). Aos 12 dias após a emergência das plântulas realizou-se o desbaste, mantendo-se uma planta por vaso. (Diniz et al., 2009b).

Durante o transcorrer da pesquisa foram realizadas capinas manuais dentro dos vasos para evitar a competição por água e nutrientes presentes no substrato, neste período o solo sempre

Tabela 1. Características físicas (A) e químicas (B) do solo no qual cultivou-se a mamona

\begin{tabular}{|c|c|c|c|c|c|c|c|c|c|c|c|}
\hline \multicolumn{2}{|c|}{ Densidade $\mathrm{kg} \mathrm{dm}^{-3}$} & \multicolumn{5}{|c|}{ Granulometria - \% } & \multirow{2}{*}{\multicolumn{5}{|c|}{ Classificação textural }} \\
\hline Global & Real & Porosidade total & Areia grossa & Areia fina & Silte & Argila & & & & & \\
\hline \multicolumn{12}{|l|}{ A) } \\
\hline 1,02 & 2,67 & 61,90 & 54,60 & 43,90 & 23,00 & 22,40 & \multicolumn{5}{|c|}{ Franco argilo arenoso } \\
\hline $\mathrm{pH}$ & \multicolumn{7}{|c|}{ Complexo Sortivo (meq $100 \mathrm{~g}^{-1}$ de solo) } & $\mathrm{CO}$ & $\mathbf{N}$ & MO & $\mathbf{P}$ \\
\hline$(1: 2,5)$ & $\mathrm{Ca}$ & $\mathrm{Mg}$ & $\mathrm{Na}$ & $\mathrm{K}$ & $\mathbf{S}$ & $\mathrm{H}+\mathrm{Al}$ & $T$ & & $\%$ & & $\mathrm{mg} / 100 \mathrm{~g}$ \\
\hline B) & & & & & & & & & & & \\
\hline 7,49 & 5,66 & 2,09 & 0,20 & 0,24 & 7,86 & 0,00 & 7,86 & 0,61 & 0,06 & 1,05 & 2,57 \\
\hline
\end{tabular}


Tabela 2. Análise química da casca usada na adubação da mamoneira

\begin{tabular}{|c|c|c|c|c|c|c|c|c|c|c|c|c|c|}
\hline Umidade & PB* & $\mathrm{CZ}^{* *}$ & $\mathbf{N}$ & $\mathbf{P}$ & $\mathrm{P}_{2} \mathrm{O}_{5}$ & K & $\mathrm{K}_{2} \mathrm{O}$ & C & $\mathrm{CaO}$ & $\mathrm{Mg}$ & MgO & 5 & MO \\
\hline \multicolumn{14}{|c|}{$\%$} \\
\hline 7,5 & 11,93 & 12,61 & 1,91 & 0,12 & 0,97 & 4,61 & 5,54 & 1,27 & 1,78 & 0,3 & 0,53 & 0,17 & 87,39 \\
\hline
\end{tabular}

Análises realizadas no Laboratório de Química do Centro Nacional de Pesquisa de Algodão

* PB: Proteína Bruta; ** CZ: Cinza

esteve em capacidade de campo, evitando assim déficit hídrico na cultura, com a realização da reposição hídrica à planta de forma manual, utilizando um regador.

A coleta dos dados para determinação dos parâmetros área foliar por planta, número de folhas e número de nós foi realizada em intervalos de quinze dias, num total de seis períodos de coleta. Utilizou-se na medição da área foliar régua graduada em centímetros.

A área foliar foi calculada pela fórmula $\mathrm{S}=0,2439 \times(\mathrm{P}+$ $\mathrm{T})^{2,0898}$, utilizando valores de comprimento da nervura principal (P) e média do comprimento das duas nervuras laterais (T). (Severino et al., 2004).

Na determinação dos valores para as variáveis massa seca das folhas, massa seca da raiz e massa seca do cacho utilizouse uma balança digital com resultados expressos em gramas.

Os dados obtidos foram submetidos à análise de variância (Teste F) e teste de Tukey a 5\% de probabilidade e comparados através de modelos regressão (Ferreira, 1996).

\section{RESULTADOS E DISCUSSÃO}

Na Tabela 3 são apresentados os resumos da análise de variância para a massa seca das folhas (MSF), massa seca da raiz (MSR) e massa seca do cacho (MSC). Observa-se que apenas a massa seca do cacho sofreu efeito significativo para os fatores tipos de casca e doses de nitrogênio. No entanto, as interações entre os fatores não demonstraram diferenças significativas.

Tabela 3. Resumos da anál ise da variância para as variáveis agronômicas produtivas estudadas na mamoneira, submetida à adubação com casca de mamona e doses de adubos químicos

\begin{tabular}{lrrcc}
\hline \multirow{2}{*}{ FV } & \multirow{2}{*}{ GL } & \multicolumn{3}{c}{ Quadrado médio } \\
\cline { 3 - 5 } TCASCA(C) & 1 & MSF & MSR & MSC \\
DOSE (D) & 3 & $2,20^{\text {ns }}$ & $3,47^{\text {ns }}$ & $12,10^{* *}$ \\
C x D & 3 & $0,51^{\text {ns }}$ & $1,09^{\text {ns }}$ & $3,10^{* *}$ \\
Resíduo & 24 & $0,91^{\text {ns }}$ & $0,48^{\text {ns }}$ & $0,43^{\text {ns }}$ \\
\hline CV\% & 1,40 & 0,82 & 0,96 \\
\hline
\end{tabular}

FV - Fontes de Variação; C - Tipos de Casca; D- Doses de Adubos Químicos; MSF- Massa Seca das Folhas; MSR-Massa Seca da Raiz e; MSC- Massa Seca do Cacho;** Significativo a 1\% de probabilidade; ${ }^{\text {ns } N a ̃ o ~ s i g n i f i c a t i v o ~}$

Conforme Oliveira et al. (2009), em estudos com a mamoneira acompanhando seu desenvolvimento inicial sob diferentes fontes e doses de matéria orgânica cultivada em vaso, a mamoneira responde a fertilização orgânica, a qual além de fornecer nutrientes, melhora as características físicas e químicas e biológicas do solo, como aeração e retenção de umidade.
O cultivo da mamoneira BRS Energia foi realizado em regime de sequeiro, para tanto atendeu-se a suplementação hídrica na diretriz de Souza et al. (2007) que constatam ser mais vantajosa sua aplicação no início do crescimento da cultura, período de grande demanda hídrica, para se alcançar ganhos significativos de produtividade, adequando melhores ajustes no sistema produtivo da mamoneira.

De acordo com Lima et al (2008b), em função da alta demanda evapotranspirométrica proporcionada pela alta radiação da região semiárida, a evapotranspiração é superior ao total precipitado, ocorrendo déficit hídrico em quase todos os meses do ano, tendo-se a necessidade de suplementação hídrica.

A Tabela 4 mostra os valores médios das variáveis de produção da mamoneira. Nota-se que os tipos de casca moída e natural apresentaram resultados estatisticamente diferentes unicamente para a massa seca do cacho, sendo constatado a superioridade da casca moída em relação a natural.

Tabela 4. M édias estimadas para as variáveis agronômicas produtivas estudadas na mamoneira, submetida à adubação com casca de mamona

\begin{tabular}{cccc}
\hline & \multicolumn{3}{c}{ Variáveis } \\
\cline { 2 - 4 } Fatores & MSF & MSR & MSC \\
\cline { 2 - 4 } & \multicolumn{3}{c}{} \\
Tipos de casca & & & \\
Natural & $7,93 \mathrm{a}$ & $4,87 \mathrm{a}$ & $4,86 \mathrm{~b}$ \\
Moída & $8,45 \mathrm{a}$ & $5,53 \mathrm{a}$ & $5,31 \mathrm{a}$ \\
\hline
\end{tabular}

MSF- Massa Seca das Folhas; MSR- Massa Seca da Raiz e; MSC- Massa Seca do Cacho; Para cada fator e coluna, médias seguidas de mesma letra não diferem entre si pelo teste de Tukey a nível de $5 \%$ de probabilidade

Observa-se na Figura 1, a massa seca do cacho em função das doses de adubo químico aplicadas na adubação. A dose de $90 \mathrm{~kg} \mathrm{ha}^{-1} \mathrm{de} \mathrm{N}$ se sobressaiu em relação às demais.

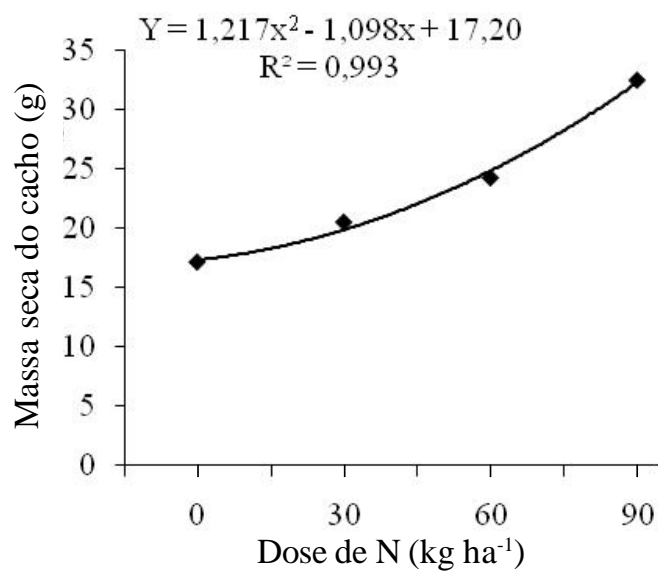

Figura 1. Massa seca do cacho da mamoneira BRS Energia em função das doses 0, 30, 60 e $90 \mathrm{~kg} \mathrm{ha}^{-1}$ de $\mathrm{N}$ aplicadas na adubação 
A casca, em sua forma primária, é um componente de origem orgânica que usado na adubação propicia a formação de macroporos no substrato que facilitam as trocas gasosas e a distribuição da água, no entanto, tem decomposição muito lenta, de forma que sua contribuição como material fornecedor de nutrientes é pouco significativa (Lima et al., 2005).

Os resultados mais expressivos para as características de crescimento área foliar por planta, número de folhas, e número de nós estudadas obteve-se na adubação com casca moída, que alcançou superioridade em relação à casca natural, sendo significativa apenas a interação casca moída com as doses crescentes de nitrogênio nos diferentes dias após plantio (DAP).

A área foliar por planta (Figura 2A) e o número de folhas (Figura 2B) respectivamente de 11,57 a $3577,55 \mathrm{~cm}^{2}$; de 2 a 50 folhas; nas mesmas foram encontrados os maiores valores para a dose de $90 \mathrm{~kg} \mathrm{ha}^{-1}$ de $\mathrm{N}$ estimados aos 90 DAP.

A.

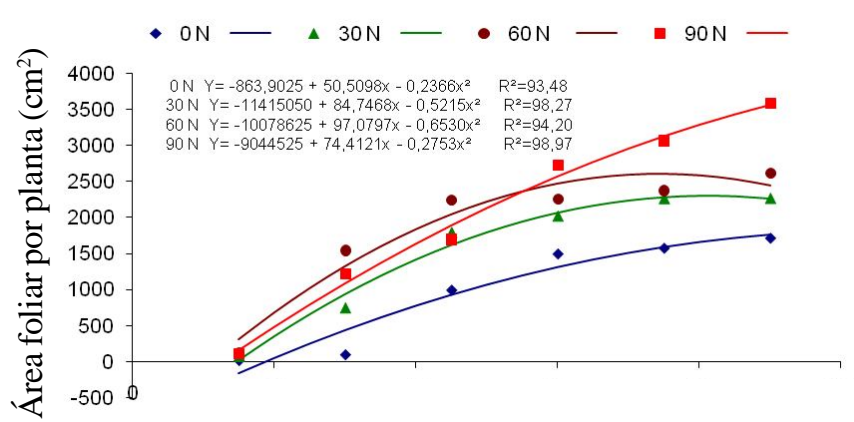

B.

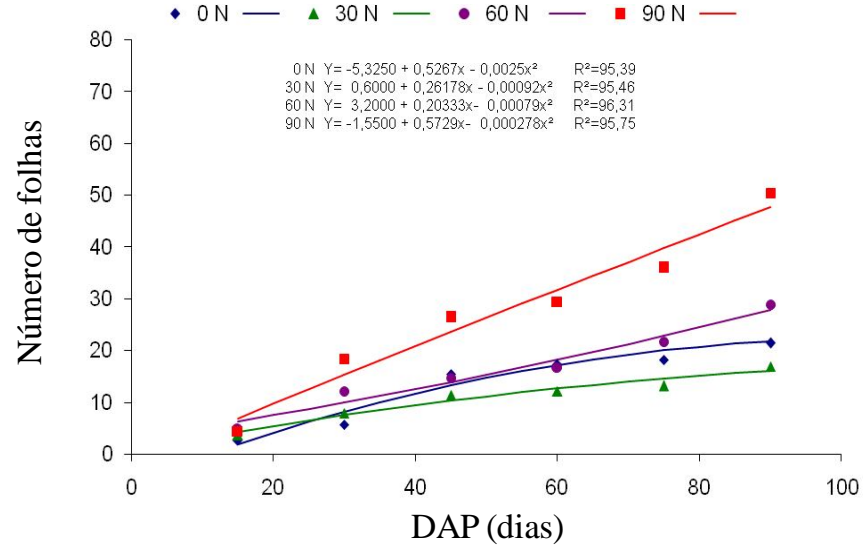

Figura 2. Área foliar por planta $(A)$ e número de fol has (B) da mamoneira BRS Energia nos diferentes dias após plantio (D AP) em função das doses 0, 30,60 e $90 \mathrm{~kg} \mathrm{ha}^{-1}$ de $\mathrm{N}$ com casca de mamona moída aplicadas na adubação

A maior área foliar por planta obteve-se na dose de 90 $\mathrm{kg} \mathrm{ha}^{-1}$ de $\mathrm{N}$ superando respectivamente as demais quantidades de 60, 30 e $0 \mathrm{~kg} \mathrm{ha}^{-1}$ de $\mathrm{N}$ em 26,93, 36,63 e 52,07\%. Nesta tendência a dose $90 \mathrm{~kg} \mathrm{ha}^{-1} \mathrm{de} \mathrm{N}$ para o número de folhas superou na proporção de 42,58, 57,43 e 66,34\% respectivamente, as doses 60,0 e $30 \mathrm{~kg} \mathrm{ha}^{-1} \mathrm{de} \mathrm{N}$.

Possivelmente a utilização da casca moída, tornando-se um pó de partículas finas, facilitou a mineralização e disposição de alguns nutrientes para as plantas, caso do $\mathrm{N}$, contribuindo para reduzir a relação $\mathrm{C} / \mathrm{N}$ da mesma.
Lima et al. (2008a), estudando casca e torta de mamona avaliados em vasos como fertilizantes orgânicos, relatam que quando a casca de mamona é usada na adubação em vaso, é preciso que antes seja submetido a um processo de compostagem, decomposição ou misturada a outro material rico em $\mathrm{N}$, o que reduz a relação $\mathrm{C} / \mathrm{N}$ da mesma.

Na Figura 3, observa-se números de nós de 2 a 22. A dose de $60 \mathrm{~kg} \mathrm{ha}^{-1}$ de $\mathrm{N}$ foi a que influenciou de forma mais elevada o número de nós da mamoneira respectivamente em 14,45, 14,45 e 21,12\% em relação às demais doses de 90,0 e $30 \mathrm{~kg} \mathrm{ha}^{-1}$ de N.

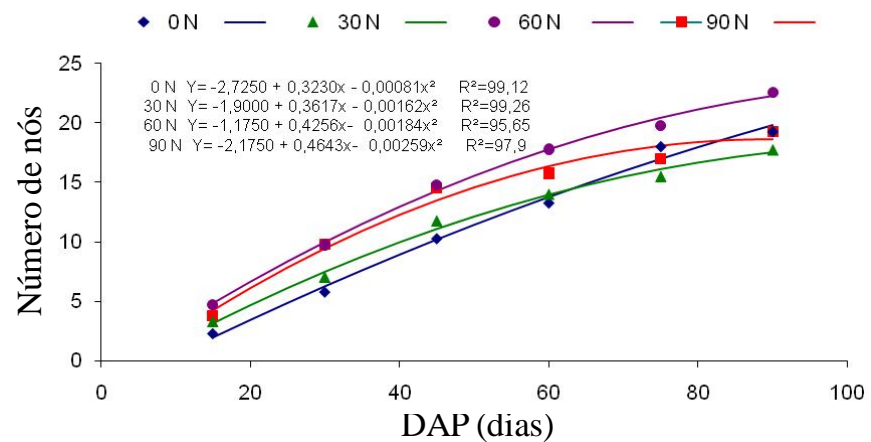

Figura 3. N úmero de nós da mamoneira BRS Energia nos diferentes dias após plantio (DAP) em função das doses 0, 30, 60 e $90 \mathrm{~kg} \mathrm{ha}^{-1}$ de $\mathrm{N}$ com casca de mamona moída aplicadas na adubação

Trabalhando com interação da adubação organo-mineral no estado nutricional das plantas de meloeiro, Oliveira et al. (2010) evidenciam que a adição do adubo orgânico ao solo favorece a disponibilidade dos nutrientes fornecidos pela adubação química.

No entanto, dificilmente um material orgânico terá todos os nutrientes essenciais na quantidade exigida pelas plantas, o que limita a utilização da adubação orgânica como única fonte de nutrientes, devendo-se utilizá-la em conjunto com a adubação mineral.

A casca de mamona é rica em $\mathrm{K}$, de acordo com Severino et al. (2006), este fator contribui de forma positiva em seu uso como adubo orgânico, além de ser uma fonte disponível nas propriedades e locais que cultivam mamona, isto ficou evidenciado em seus trabalhos científicos com os subprodutos gerados do beneficiamento e industrialização da mamona.

Nas plantas, o potássio estimula o desenvolvimento da raiz, o alongamento dos colmos, ativa cerca de 60 enzimas, controla a turgidez das plantas, o transporte de açúcar e amido, auxilia na formação de proteína, oferece à planta maior resistência às doenças, propicia melhor qualidade aos produtos vegetais e está envolvido em muitas outras funções (Perdigão et al, 2010).

Os resultados reportam ao presente estudo em que não se utilizou o K na adubação, no entanto, as plantas cultivadas tiveram um bom desenvolvimento vegetativo e resultados bastante expressivos para as características estudadas, provavelmente também, pela ação do mesmo. 


\section{CONCLUSÕES}

1. Entre as variáveis estudadas obteve-se superioridade na adubação com casca moída em relação à casca natural.

2. Para a massa seca do cacho, área foliar por planta e número de folhas a dose de $90 \mathrm{~kg} \mathrm{ha}^{-1}$ de $\mathrm{N}$ se sobressaiu em relação às demais. Já para o número de nós foi a dose de $60 \mathrm{~kg} \mathrm{ha}^{-1} \mathrm{de} \mathrm{N}$.

3. O maior valor para o número de nós foi obtido com a dose de $60 \mathrm{~kg} \mathrm{ha}^{-1}$.

\section{AgradeCIMENTOS}

Ao Centro Nacional de Pesquisa de Algodão e a Universidade Estadual da Paraíba, pelo apoio financeiro e científico na realização deste.

\section{LITERATURA CITADA}

Azevedo, D. M. P; Beltrão, N. E. de M. O agronegócio da mamona no Brasil. 2. ed. Campina Grande: Embrapa Algodão, 2007. 504p. Embrapa Informação Tecnológica

Diniz, B. L. M. T.; Távora, F. J. A. F.; Diniz Neto, M. A. Manipulação do crescimento da mamoneira através da poda em diferentes densidades populacionais. Revista Ciência Agronômica, Fortaleza, v.40, p.570-577, 2009a.

Diniz, B. L. M. T.; Távora, F. J. A. F.; Diniz Neto, M. A.; Bezerra, F. M. L. Desbaste seletivo e população de plantas na cultura da mamoneira. Revista Ciência Agronômica, v.40, p.247-255, 2009b.

Ferreira, P. V. Estatística experimental aplicada à agronomia. 2. ed. Maceió: EDUFAL. 1996. 606p.

Freitas, A. S. C.; Bezerra, F. M. L.; Silva, A. R. A.; Pereira Filho, J. V.; Feitosa, D. R. C. Comportamento de cultivares de mamona em níveis de irrigação por gotejamento em Pentecoste, CE. Revista Brasileira de Engenharia Agrícola e Ambiental, v.14, p.1059-1066, 2010.

Freitas, S. M.; Fredo, C. E. Biodiesel à base de óleo de mamona: algumas considerações. Revista Informações Econômicas, v.35, p.37-42, 2005.

Lima, C. B.; Santos Filho, S. V. dos; Santos, A. S.; Oliveira, M. Desenvolvimento da mamoneira, cultivada em vasos, sob diferentes níveis de salinidade da água em Latossolo vermelho-amarelo eutrófico. Caatinga, v.21, p.50-56, 2008a.

Lima, E. F. S.; Severino, L. S.; Albuquerque, R. C.; Beltrão, N. E. M.; Sampaio, L. R. Casca e torta de mamona avaliados em vasos como fertilizantes orgânicos. Caatinga, v.21, p.102106, 2008b.

Lima, E. F. S.; Severino, L. S.; Silva, M. I. L.; Vale, L. S. Crescimento inicial de mudas de mamoneira em substrato contendo lodo de esgoto e casca de amendoim. Revista Brasileira de Oleaginosas e Fibrosas, v.9, p.887-891, 2005.
Lima, R. L. S.; Severino, L. S.; Ferreira, G. B.; Sofiatti, G. B. F; Sampaio, L. R.; Beltrão, N. E. M. de. Casca de mamona associada a quatro fontes de matéria orgânica para a produção de mudas de pinhão-manso. Revista Ceres, v.58, p.232-237, 2011.

Lira, M. A.; Barreto, F. P. Oleaginosas com fonte de matériaprima para a produção de biodiesel. 1.ed. Natal: EMPARN, 2009. 64p.

Lopes, G. E. M.; Vieira, H. D.; Jasmim, J. M.; Shimoya, A.; Marciano, C. R. Casca do fruto da mamoneira como substrato para as plantas. Revista Ceres, v.58, p.350-358, 2011.

Maia, S. S. S.; Pinto, J. E. B. P.; Silva, F. N.; Oliveira, C. Influência da adubação orgânica e mineral no cultivo do bamburral (Hyptis suaveolen (L.) Poit.) (Lamiaceae). Revista Brasileira de Ciências Agrárias v.3, p.327-331, 2008.

Oliveira, A. E. S.; Sá, J. R.; Medeiros, J. F.; Nogueira, N. W.; Silva, K. J. P. Interação da adubação organo-mineral no estado nutricional das plantas. Revista Verde de Agroecologia e Desenvolvimento Sustentável, v.5, p.53-58, 2010.

Oliveira, F. A.; Oliveira Filho, A. F.; Medeiros, J. F.; Almeida Júnior, A. B.; Linhares, P. C. F. Desenvolvimento inicial da mamoneira sob diferentes fontes e doses de matéria orgânica. Caatinga, v.22, p.206-211, 2009.

Perdigão, P. C. N.; Costa, R. N. T.; Medeiros, A. T.; Silva, L. A.; Santos, M. D. S. Efeitos de níveis de água e adubação potássica no desenvolvimento do cajueiro anão-precoce, BRS - 189. Revista Brasileira de Ciências Agrárias, v.5, p.9094, 2010.

Rodrigues, H. C. A.; Carvalho, S. P.; Souza, H. A.; Carvalho, A. A. Cultivares de mamoneira e adubação nitrogenada na formação de mudas. Revista Maringá, v.32, p.471-476, 2010.

Severino, L. S.; Cardoso, G. D.; Vale, L. S.; Santos, J. W. Método para determinação da área foliar da mamoneira. Revista Brasileira de Oleaginosas e Fibrosas, v.8, p.753-762, 2004.

Severino, L. S.; Ferreira, G. B.; Morais, C. R. A.; Gondin, T. M. S.; Freire, W. S.A.; Castro, D. A.; Cardoso, G. B.; Beltrão, N. E. de M. Adubação química da mamoneira com macro e micronutrientes em Quixeramobim, CE. Campina Grande, PB. Embrapa Algodão, 2005. 23p. Boletim de Pesquisa e Desenvolvimento, 61

Severino, L. S.; Freire, R. M. M. Subprodutos. In: coleção quinhentas perguntas, quinhentas respostas, o produtor pergunta, a Embrapa responde. 1.ed. Brasília: Embrapa Informação Tecnológica, 2006. 230p.

Souza, A. S.; Távora, F. J. A. F.; Pitombeiras, J. B.; Bezerra, F. M. L. Épocas de plantio e manejo da irrigação para a mamoneira. II - Crescimento e produtividade. Revista Ciência Agronômica, v.38, p.422-429, 2007.

Távora, F. J.; Barbosa Filho, M. Antecipação de plantio, com irrigação suplementar, no crescimento e produção da mandioca. Pesquisa Agropecuária Brasileira, v.29, p.19151926, 1994. 